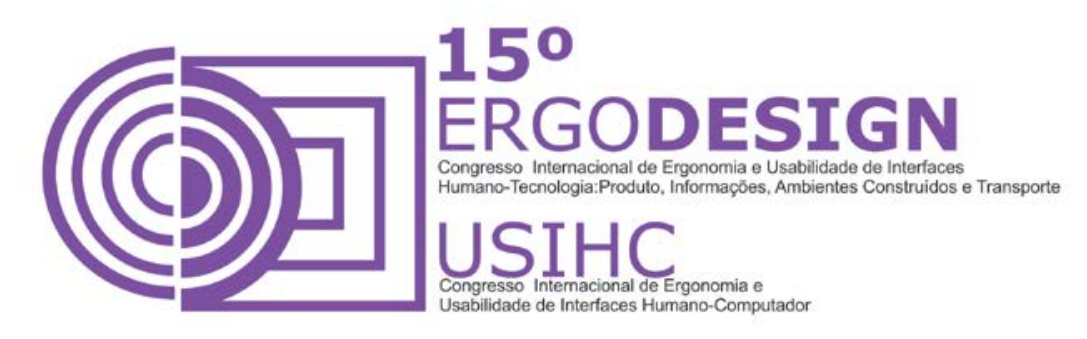

\title{
IDENTIDADE E TERRITÓRIO SOB A ÓTICA DO PACIENTE PEDIÁTRICO: UMA APLICAÇÃO DO POEMA DOS DESEJOS
}

\section{IDENTITY AND TERRITORY FROM PERSPECTIVE PEDIATRIC PATIENT: AN APPLICATION OF WISH POEMS}

\author{
OLIVEIRA, Juliana Simili de (1); \\ PINHEIRO, Ethel (2); \\ ABDALLA, José Gustavo Francis (3). \\ (1) Universidade Federal do Rio de Janeiro, Mestre. \\ e-mail: julianasimili@gmail.com \\ (2) Universidade Federal do Rio de Janeiro, Doutora. \\ e-mail: ethelp31.3@gmail.com \\ (3) Universidade Federal de Juiz de Fora, Doutor. \\ e-mail: gustavofrancis@globo.com
}

\begin{abstract}
RESUMO
A hospitalização na infância representa a estranheza, o ausentar-se do próprio mundo rompendo com seu cotidiano e hábitos. Visando compreender a importância do ambiente construído na humanização de pediatrias, analisou-se a percepção desses pacientes sobre tal espaço, através da ferramenta Poema dos Desejos. Discutiu-se acerca da necessidade de elementos que remetam às noções de identidade e território no projeto de arquitetura. A conclusão é que a arquitetura deve contribuir para o bem-estar, propondo respeito, dignidade e conforto no enfrentamento da doença. O desafio está em pensar ambientes pediátricos como lugares que espelhem significados que darão continuidade ao vivido no cotidiano.

Palavras-chave: Arquitetura; Pediatria; Identidade; Território.
\end{abstract}

\section{ABSTRACT}

Hospitalization in childhood is the strangeness, the absence of the world itself, breaking their daily lives and habits. In order to understand the importance of the built environment in the humanization of pediatrics, the perception of these patients on this space was analyzed through the tool Wish Poem. Was 


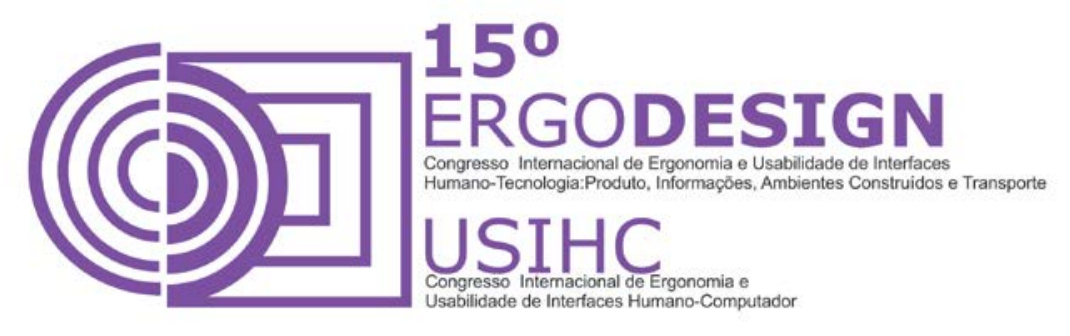

discussed on the need of elements that refer to notions of identity and territory in architectural design. The conclusion is that the architecture should contribute to the welfare, proposing respect, dignity and comfort during illness. The challenge is to think pediatric environments as places that reflect meanings that will continue the lived in daily life.

Keywords: Architecture, Pediatric, Identity, Territory.

\section{INTRODUÇÃO}

Entende-se por infância o período de formação e desenvolvimento tanto físico quanto psicossocial do ser humano. Cronologicamente falando, é considerada criança "a pessoa até doze anos de idade incompletos, e adolescente aquela entre doze e dezoito anos de idade" (BRASIL, 1990).

No contexto infantil, a hospitalização representa a estranheza, o ausentar-se do próprio mundo rompendo com seu cotidiano e hábitos. Ao abandonar seu espaço diário, em uma mudança de sua rotina e na de seus familiares, a criança passa a conviver com a doença e a confrontar a dor, a limitação física e a passividade, fazendo aflorar sentimentos de culpa, punição e medo da morte (ALMEIDA, 2005; MITRE, 2004).

Neste sentido, "a hospitalização na infância pode se configurar como uma experiência potencialmente traumática" (SANTA ROZA apud MITRE et. al., 2004), já que o afastamento do seu cotidiano e do ambiente familiar configura-se na perda de suas referências. Quando a criança ou o adolescente passam por uma internação, o curso natural de seu desenvolvimento é modificado, bem como a sua maneira de ver o mundo.

Emerge então a necessidade de se propor meios que levem os pacientes pediátricos a elaborarem suas experiências, ordenando seus sofrimentos e frustrações e possibilitando que eles expressem seus sentimentos em relação ao momento tão particular que estão vivendo. Um desses meios diz respeitos aos mecanismos arquitetônicos-espaciais e sua capacidade de facilitar a humanização dos ambientes pediátricos, sem perder de vista a questão da funcionalidade (OLIVEIRA, 2012).

Cabe ainda ressaltar que o conjunto de propostas que englobam a humanização responde a uma questão crucial levantada por uma abordagem mais integral da enfermidade na infância: a criança hospitalizada apresenta outras necessidades, não médicas, que precisam ser atendidas com igual relevância (OLIVEIRA, 1993).

Visando compreender a importância do ambiente construído para a humanização nos espaços de saúde pediátricos, foi realizada uma análise da percepção dos pacientes sobre o espaço em que estão inseridos durante a hospitalização. Para isso, foi utilizada como metodologia uma aplicação do Poema dos Desejos na enfermaria pediátrica da Santa Casa de Misericórdia de Juiz de Fora (SCM-JF). Por meio de uma análise qualitativa, os dados foram tabulados e sintetizados de acordo com as respostas semelhantes e recorrentes. Assim, o texto a seguir visa discutir a necessidade de se inserir elementos que remetam às noções de identidade e 


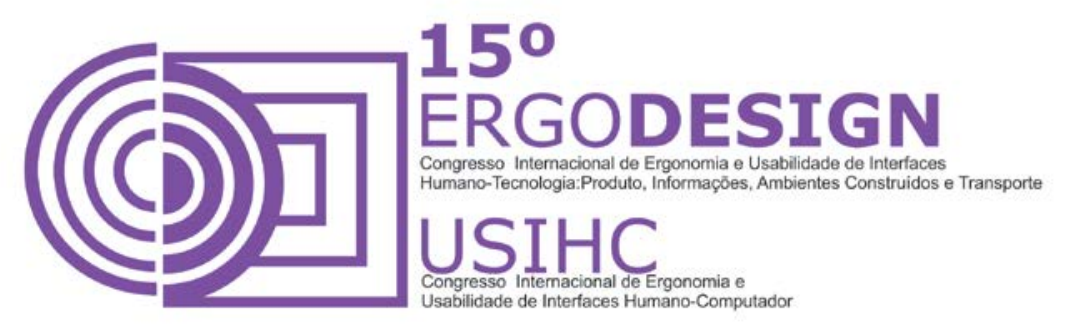

território durante um projeto de arquitetura de enfermarias pediátricas. Busca considerar questões da realidade humana e social no contexto da saúde, visto que o ato de projetar está vinculado a um cenário que foge ao contexto estritamente técnico-funcional e necessita tornarse sensivelmente tangível pelo imaginário do usuário das unidades de saúde.

\section{IDENTIDADE E TERRITÓRIO EM ARQUITETURA}

Ao adentrarmos na discussão a respeito de ambientes de saúde, é preciso primeiramente se compreender que, conforme Malkin (2012), o cuidado em saúde não pode ser dissociado do ambiente no qual é efetuado. Para ela, nossos sentidos respondem ao ambiente que, em troca, logo influência em nossa fisiologia. Fischer (1984) corrobora tal influência quando diz que o ambiente atua sobre o ser humano que, por sua vez age sobre os fatores espaciais que 0 determinam, sendo tal relação que determina o valor do espaço e a orientação da conduta. $\mathrm{O}$ espaço é, para ele, o espelho de um mundo fabricado, modelado pelo homem, sendo os elementos arquitetônicos uma das matrizes da experiência individual e coletiva, tecendo à sua volta um contexto que é humano e coletivo.

Uma forma de compreender a relação do espaço é a partir da maneira como o homem utiliza o lugar, como o trata afetiva e cognitivamente. Trata-se de um espaço vivido, ou seja, carregado por experiências sensori-motora, tátil, visual, afetiva e social, determinando através das relações estabelecidas com ele, um conjunto de significações impregnadas de valores culturais próprios. Nesta relação, o espaço arquitetônico não se reduz às suas propriedades materiais: é estruturado como uma linguagem que comunica uma mensagem sobre seus ocupantes, sobre as suas funções (FISCHER, 1984). Como afirma Hall (1977), praticamente tudo que o homem é e faz vincula-se à experiência do espaço, em uma síntese de muitos insumos sensoriais.

"[...] Porque o espaço não é só cavidade vazia, 'negação de solidez': é vivo e positivo. Não é apenas um fato visual: é, em todos os sentidos, e, sobretudo num sentido humano e integrado, uma realidade vivida." (Zevi, 2009, p. 217)

A melhor maneira de conceber um espaço arquitetônico, portanto, implica em conhecer as características dos usuários do espaço e as atividades que predominantemente serão desenvolvidas, para que se compreendam suas problemáticas e para que sejam projetados ambientes adequados a cada situação particular. Ou seja, em um espaço de saúde a situação vivenciada por cada um dos atores do sistema é de fundamental importância se o objetivo é propor ambientes favoráveis ao bem estar e mais humanizados. Neste caso, a arquitetura surge com o intuito de aproximar o serviço de saúde de seus sujeitos, tornando-o mais familiar e menos agressivo.

Em particular em um ambiente de saúde pediátrico, as necessidades que os usuários podem apresentar são diferentes das dos adultos. Neste artigo entendemos que seja fundamental que o espaço físico de enfermarias pediátricas traga em si noções de identidade e território, próprios de seus usuários quando não estão em um espaço de saúde. 


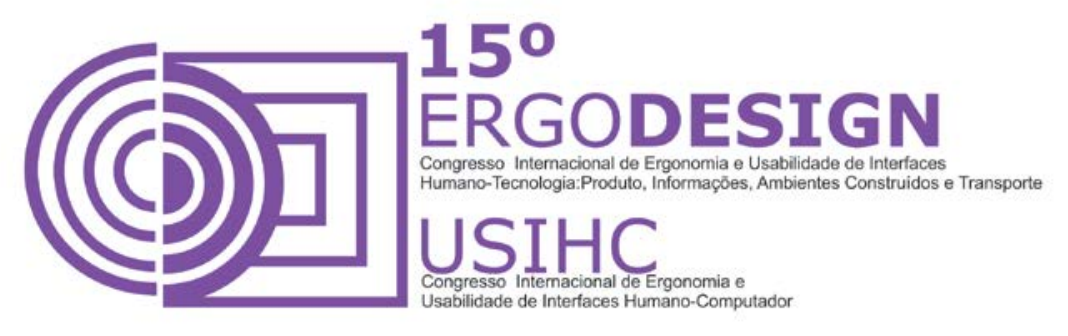

Quando dizemos que tais espaços de saúde precisam agregar identidade, cremos que tais usuários possam se apropriar e construir contextos sociais que poderão ser vivenciados por meio dos sistemas simbólicos dos quais damos sentido a nossas próprias posições (WOODWARD, 2000). Tal conceito associa-se ainda com a noção de espaço pessoal e de personalização, permitindo o ajuste de um ambiente a suas necessidades especificas (SOMMER, 1993). Essa construção identitária considera que os pacientes pediátricos possam trazer para sua experiência hospitalar elementos capazes de invocar características, signos, referências e influências de sua vivencia cotidiana, remetendo às suas características enquanto pessoa e não apenas como paciente.

Mais ainda, este paciente precisa, além de se posicionar como pessoa, poder situar-se institucionalmente, ou seja, poder falar do seu território, que pode ser definido como um universo onde se reúnem por algum tempo um conjunto de indivíduos e onde se desenrolam atividades definidas (FISHER, 1984). Segundo Van der Voordt e Van Wegen (2013), territorialidade significa a necessidade de lugar próprio, sob controle próprio, temporário ou não, em diferentes graus. Neste sentido, a ideia de território implica frequentemente na personalização do lugar com a ajuda de marcações e de elementos de apropriação que indicam que se é de algum modo o seu ocupante (FISHER, op. cit.).

Em seu livro "Arquitetura sob o olhar do usuário", Van der Voordt e Van Wegen (2013) afirmam que as noções de espaço pessoal e territorialidade estão intimamente relacionadas, uma vez que ambos se referem entre a distância entre o indivíduo e o outro. Para ele, o território é visível, razoavelmente estático e preso a uma localização especifica. Em contrapartida, o espaço pessoal é invisível, móvel, preso a um individuo especifico e "portátil".

É fundamental ressaltar que as noções de território e identidade trazem em si valores que tendem a agregar à arquitetura elementos que aproximam da realidade humana e social, uma vez que passa a considerar a experiência de vida de seus usuários. Deste modo, a arquitetura para espaços de saúde pediátricos deve ter em vista propor um melhor uso e apropriação do espaço por parte das crianças e adolescentes, quando for o caso. Como afirma Sommer (1973), os projetistas precisam de conceitos que sejam significativos para a forma física e 0 comportamento humano, pois a arquitetura é capaz de influir nas pessoas, mesmo que isso não chegue à consciência.

\section{ESTUDO DE CASO: ENFERMARIA PEDIÁTRICA DA SANTA CASA DE MISERICÓRDIA DE JUIZ DE FORA}

A Santa Casa de Misericórdia de Juiz de Fora (SCM-JF) foi fundada em 6 de agosto de 1854 por iniciativa de um dos pioneiros do plantio de café na região e é atualmente o maior hospital da Zona da Mata Mineira. Está localizada na Avenida Barão do Rio Branco, região central da cidade de Juiz de Fora. É composta por 28 estruturas, edificadas ao longo de mais de um século, sendo constituídas por diferentes estilos arquitetônicos. A Capela Nosso Senhor dos Passos, por exemplo, foi construída com feições neogóticas, com sua torre pontiaguda e recoberta por chapas metálicas (FUNALFA, 2004). Existem também estruturas em pavilhões e o monobloco vertical, com 15 pavimentos, onde efetivamente funciona o Hospital atualmente. 


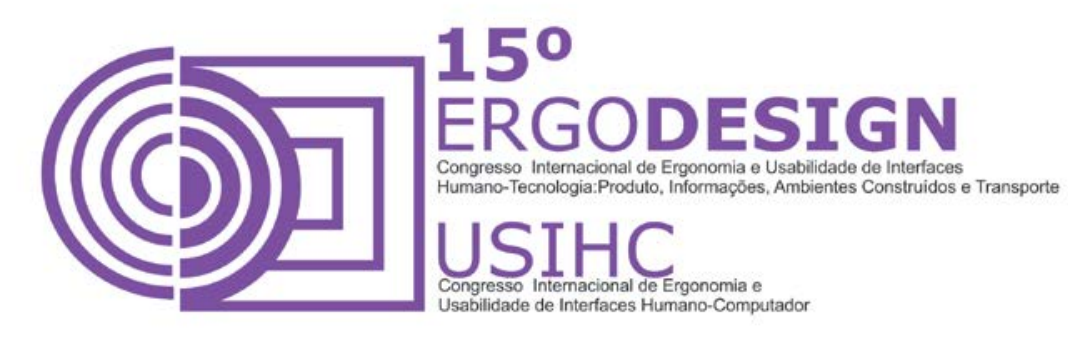

Morfologicamente, este prédio se distribui sempre em três alas, sendo que no caso particular da pediatria essas alas são designadas por cores: amarela, verde e azul (figura 1) (OLIVEIRA, 2012).

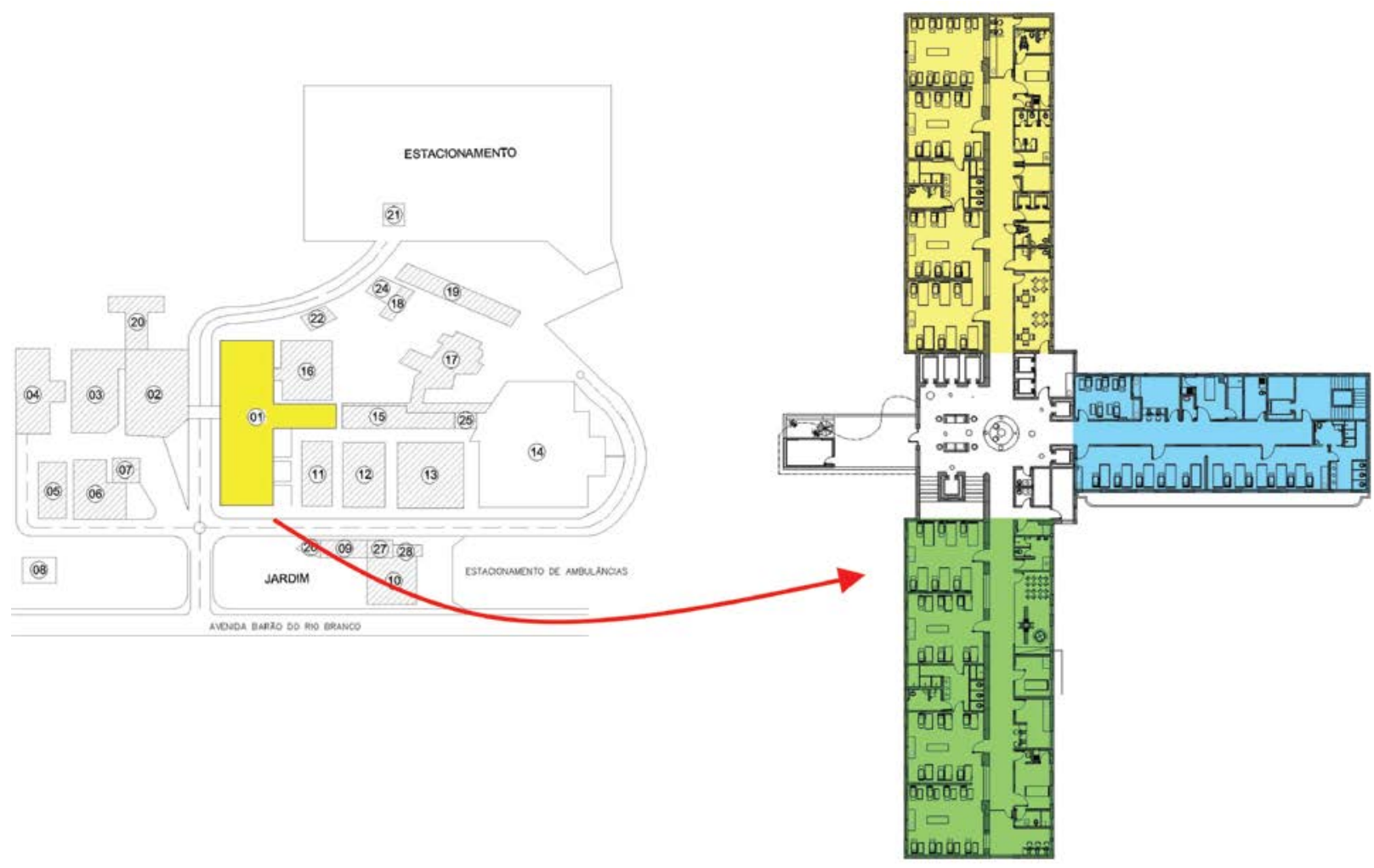

Figura 1 - Implantação da SCM-JF e planta baixa esquemática do andar da Pediatria (fonte: o autor).

\subsection{Metodologia}

O objeto de análise deste trabalho foi a Santa Casa de Misericórdia de Juiz de Fora, por este se constituir em um hospital geral com enfermaria pediátrica de grande relevância para a cidade de Juiz de Fora e a região da Zona da Mata de Minas Gerais e apresentar características espaciais que permitissem resultados relevantes para a pesquisa. Além disso, foi o hospital que apresentou a amostragem mais considerável quantitativamente: 10 pacientes. É preciso se observar que nem todos os pacientes participaram da pesquisa, uma vez que apresentavam limitações físicas e/ou psicológicas, decorrentes de seu estado de saúde.

Os dados utilizados neste artigo foram obtidos durante o desenvolvimento da pesquisa de mestrado de uma das autoras e reinterpretados sob a ótica da disciplina de Doutorado 


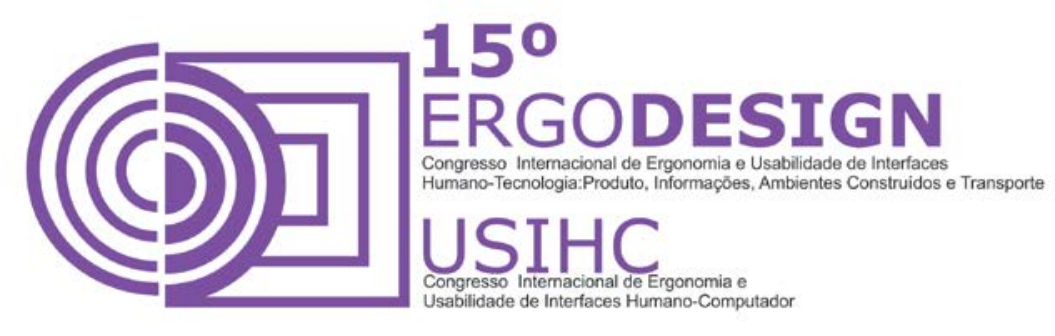

"Arquitetura e Projeto do Lugar", realizada no primeiro trimestre de 2014. A pesquisa completa abrangeu aplicações de diversos instrumentos (leitura espacial, questionário, Poema dos Desejos...) e diferentes usuários (pacientes, acompanhantes e equipe de saúde - médicos, enfermeiros etc.), porém, neste artigo, busca-se interpretar apenas o olhar do paciente.

O instrumento aplicado para esta pesquisa continha a seguinte sentença aberta: "Eu gostaria que esta pediatria fosse (ou tivesse)...". Esta frase faz parte do Wish Poem (Poema dos Desejos) e foi desenvolvida por Henry Sanoff (SANOFF, 1991 apud RHEINGANTZ et. al., 2009). Trata-se de um instrumento não-estruturado e de livre expressão, que incentiva e se baseia na espontaneidade das repostas, onde os usuários de um determinado ambiente declaram, por meio de um conjunto de sentenças escritas ou de desenhos, suas necessidades, sentimentos e desejos relativos ao edifício ou ambiente analisado (RHEINGANTZ et. al., 2009).

Cabe aqui ressaltar que este trabalho foi submetido ao Comitê de Ética em Pesquisa da instituição supracitada e foi realizado de acordo com os preceitos éticos estabelecidos pela Resolução $n^{\circ}$ 196, de 10 de outubro de 1996, do Conselho Nacional de Saúde sobre as normas regulamentadoras de investigação envolvendo seres humanos.

\subsection{Perfil dos pacientes que participaram da pesquisa}

Dez pacientes pediátricos da Santa Casa de Misericórdia de Juiz de Fora contribuíram para a pesquisa. Deste total de pacientes, $60 \%$ eram do sexo masculino e $40 \%$ do feminino. A maior parte, cerca de $90 \%$, residia em Juiz de Fora e os outros $10 \%$ em cidades da região. Todos que estavam em idade escolar, frequentavam uma escola. A idade dos entrevistados foi bastante variada, conforme pode ser observado no gráfico abaixo:

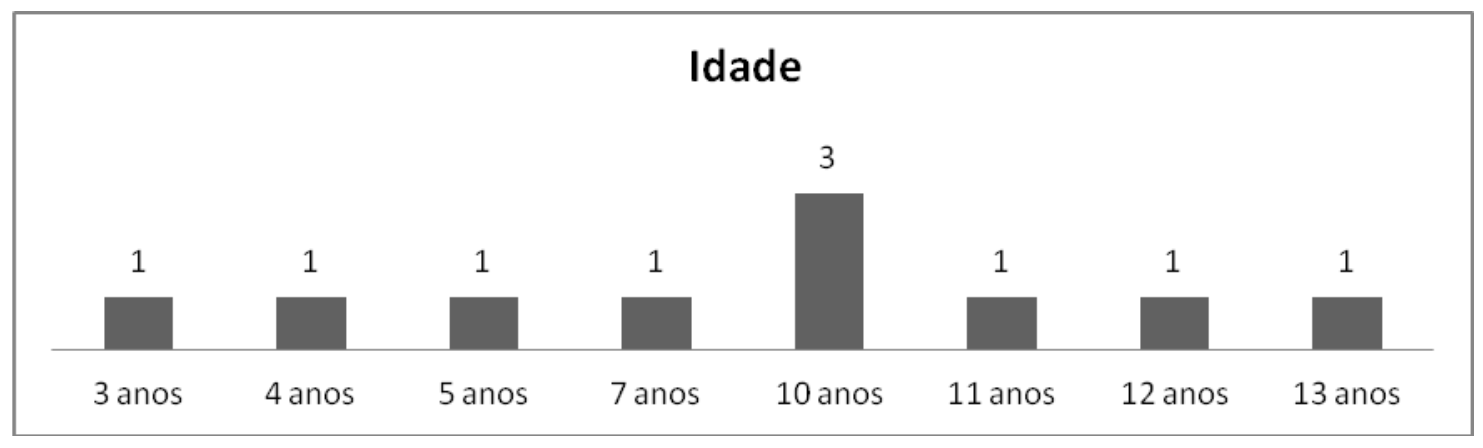

Gráfico 1 - Idade dos pacientes entrevistados na SCM-JF (fonte: a autora). 


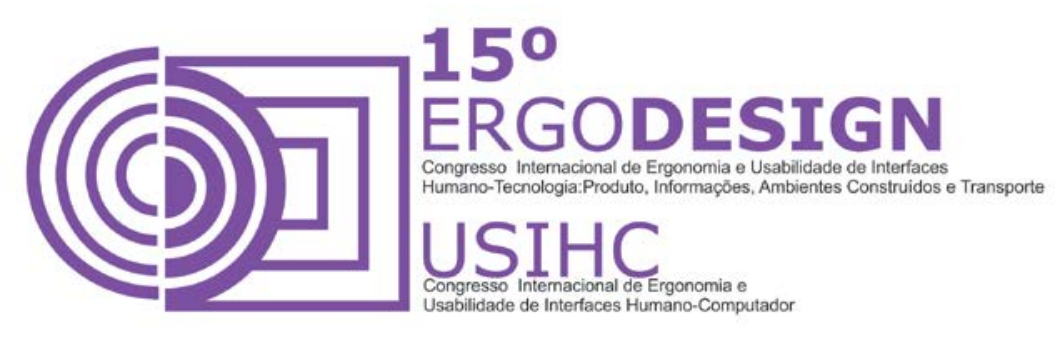

\subsection{Tabulação e análise dos resultados obtidos}

A percepção dos pacientes pediátricos em relação aos seus ambientes é foco de investigação desta pesquisa, através da utilização do "Poema dos Desejos", um dos instrumentos metodológicos aplicáveis em Avaliação Pós-ocupação. Após a aplicação dos instrumentos, a tabulação das respostas configurou a criação de diversas categorias, através da sintetização de informações semelhantes e recorrentes.

Deste modo, foram identificados quatro categorias de desejos: recreação e elementos lúdicos, adequação de infra-estrutura ao paciente, apoio para presença dos pais e o atendimento e relacionamento com a equipe do hospital (gráfico 2).

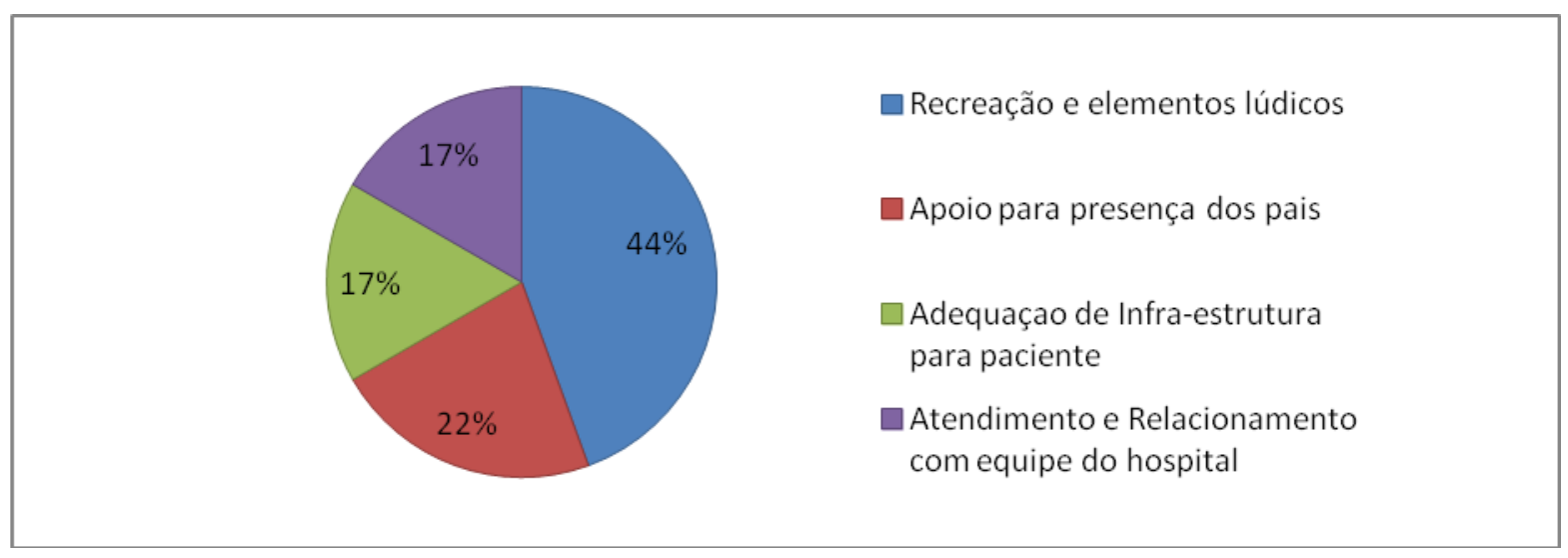

Gráfico 2 - Desejos dos pacientes pediátricos (fonte: a autora).

A solicitação definida como "recreação e elementos lúdicos" é a categoria que obteve maior destaque e resulta de solicitações que envolvem desejos por mais brinquedos, presença de animais, aparelhos multimídia nos quartos (TV, DVD, laptops, câmeras fotográficas) e parquinhos. Observando esta característica in-loco, é possível constatar que há poucos elementos que contribuem para a recreação e que fazem referencia ao imaginário lúdico da criança e do adolescente. Durante as visitas ao local, foi possível perceber que não há no hospital uma área dedicada à recreação dos pacientes. Onde teoricamente deveria ser a brinquedoteca há apenas uma TV, uma longarina e alguns poucos brinquedos (figura 2). A área aberta em que teoricamente deveriam ocorrer atividades recreativas configura-se em um pequeno pátio, sem qualquer tipo de equipamento (figura 3). A brinquedoteca móvel, segundo os funcionários do local, é pouco utilizada, já que seu uso depende de um funcionário treinado, que não está no local diariamente. Deste modo, foi observado ao longo das visitas que as crianças e pré-adolescentes brincam pelos corredores e/ou com brinquedos trazidos de casa pelos pais. 


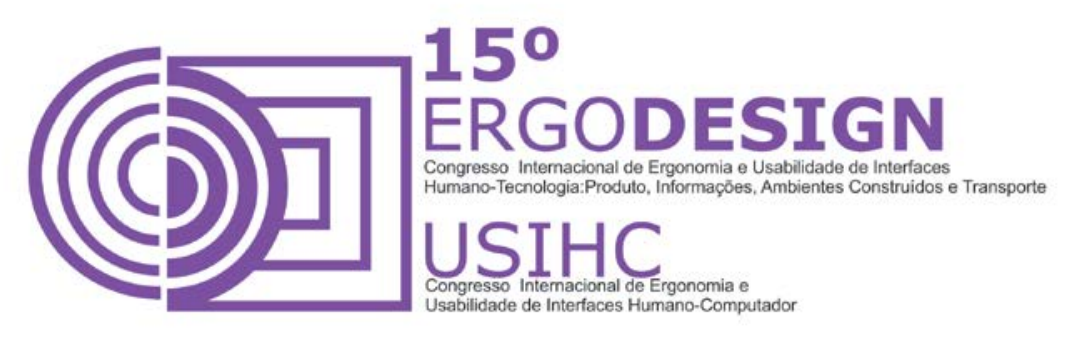

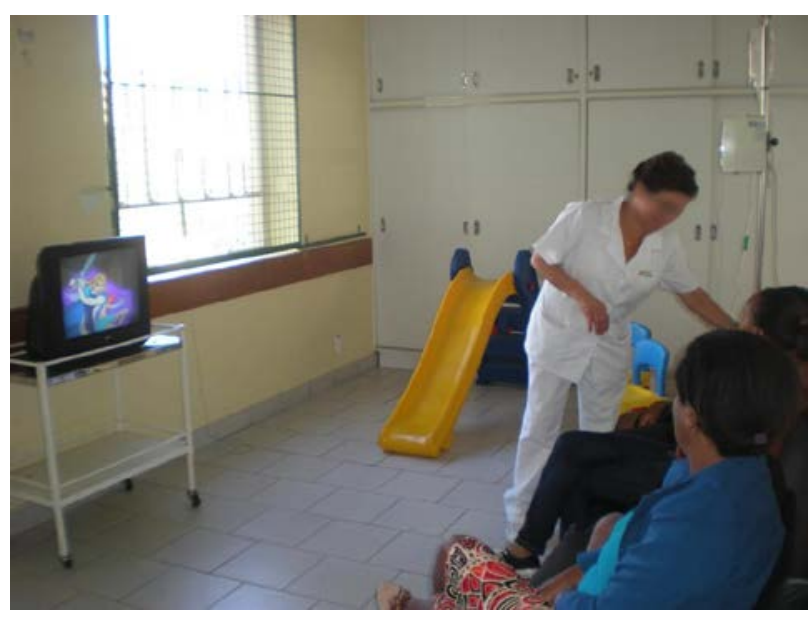

Figura 2 - Brinquedoteca / Sala de TV (fonte: a autora).

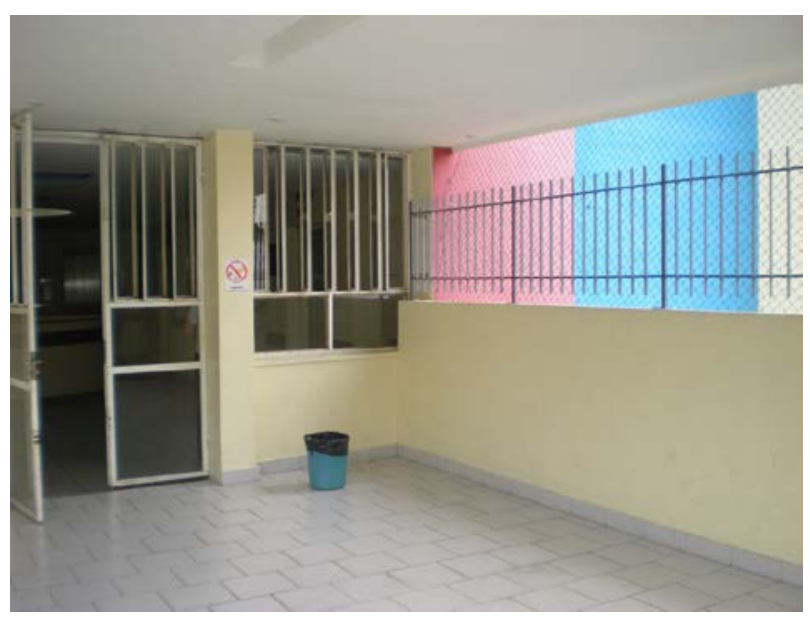

Figura 3 - Pátio de recreação (fonte: a autora).

Através de um olhar técnico, percebemos que a criança anseia por elementos que remetam a seu cotidiano, incorporando sua experiência diária também no espaço hospitalar. A criança quando em um hospital continua sendo criança e possui outras necessidades que fogem do contexto médico. Ela anseia por uma identidade extra-hospitalar e mesmo neste espaço anseia por seu universo particular.

Com 22\% das respostas, a segunda categoria que mais apresentou solicitações foi o "apoio para presença dos pais". Nesta foi agrupadas respostas que pediam por camas confortáveis para os acompanhantes, presença do pai e da mãe (apenas um estava presente) e para que os pais pudessem fazer as refeições junto com as crianças e não no refeitório. Tais respostas demonstram um anseio pela presença dos pais, que é direito garantido pelo Estatuto da Criança e do Adolescente (BRASIL, 1990), mas indo além da presença física em si. Eles queriam a vivência de situações cotidianas cerceados no contexto hospitalar. Mais ainda, a questão da infra-estrutura inadequada e desconfortável para os pais afetava a vivência das crianças, que se sentiam culpadas pelos pais passarem por tal situação de desgaste, visto que as condições para permanência não proporcionavam nenhum conforto ou até mesmo dignidade. Assim, as condições influenciavam na integridade física e moral dos usuários (figura 4).

A terceira categoria analisada foi denominada de "adequação de infra-estrutura para o paciente", consistindo em $17 \%$ das respostas e solicitavam adequação de mobiliário, com camas que atendessem à estatura de todos os pacientes, travesseiros para todos os pacientes (observou-se que havia certo revezamento) e melhoria da infra-estrutura para as crianças se alimentarem no quarto (figura 5). Observou-se situações em que pacientes maiores ficavam em 


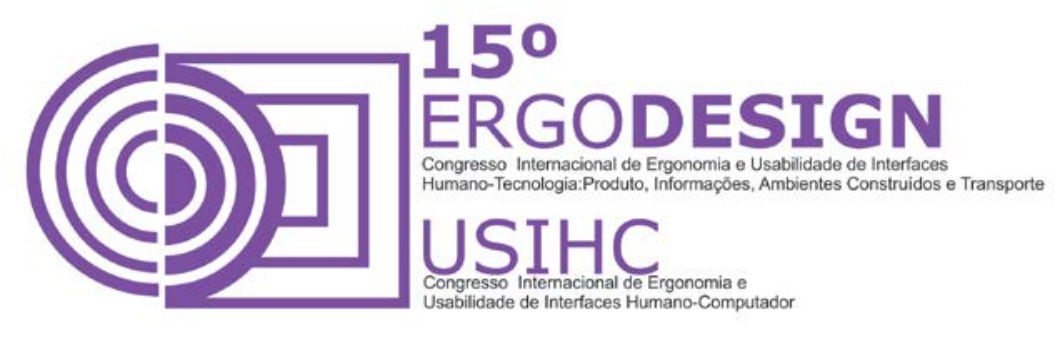

camas que não comportavam seu tamanho, ou de crianças pequenas que não queriam mais ficar em berços, por exemplo. Cabe ressaltar a necessidade de se incorporar escalas equivalentes aos usuários do espaço. Mais ainda, a adequação do espaço físico ao público alvo é de fundamental importância, a fim de tornar o espaço funcional e evitando negligenciar as expectativas do paciente infantil, evitando situações que contribuam para um deslocamento do paciente em relação ao espaço e desconsiderem sua vivência. Corrobora-se o fato de que a criança anseia por familiarização com o ambiente, buscando sentir-se mais próxima do lar.
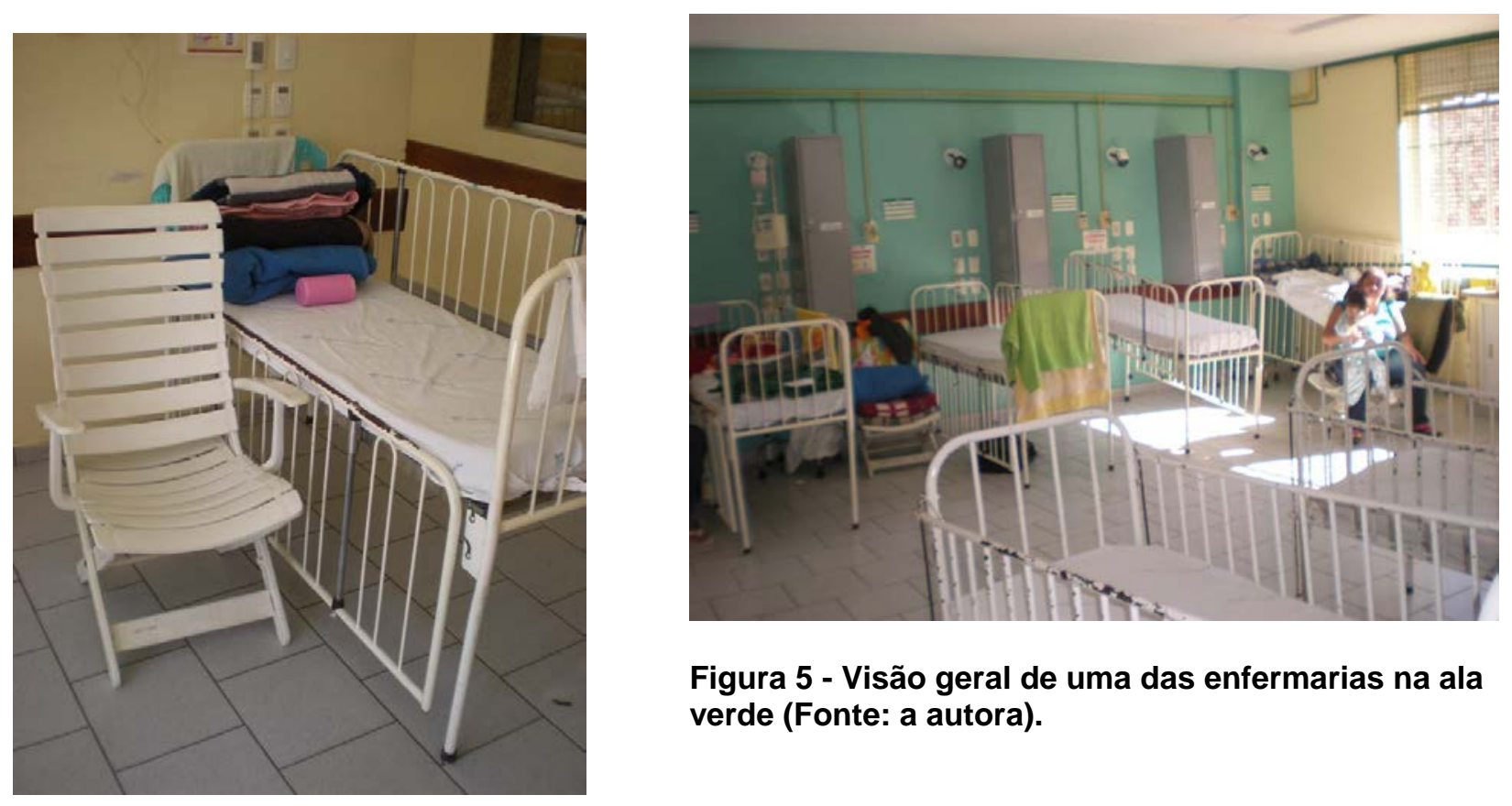

Figura 5 - Visão geral de uma das enfermarias na ala verde (Fonte: a autora).

Figura 4 - Detalhe da cadeira de acompanhantes (fonte: a autora).

Por fim, $17 \%$ dos desejos dos pacientes pediátricos diziam respeito ao "atendimento e relacionamento com a equipe do hospital", com solicitações por "enfermeiras mais pacientes", maior opção no cardápio de alimentação e melhorias nos usos dos banheiros das enfermarias, que eram coletivas com até seis leitos de pacientes. Através desse resultado em particular, é possível observar o anseio da criança por carinho e cuidado nas situações corriqueiras, extrapolando o âmbito do contexto médico. 


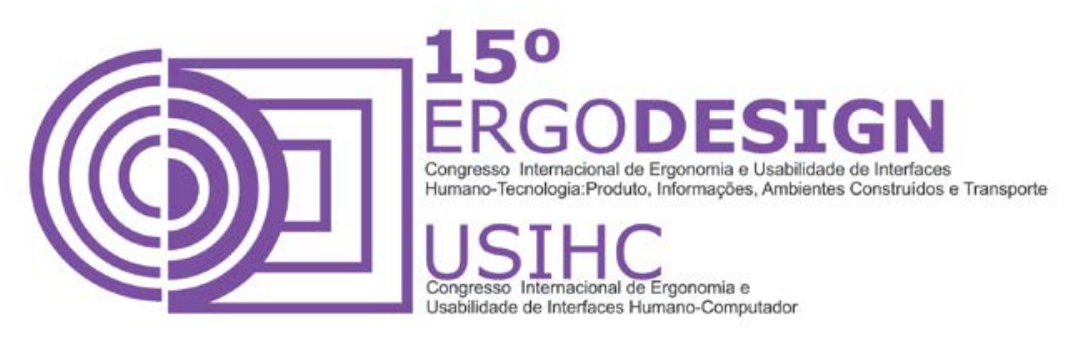

\section{CONSIDERAÇÕES FINAIS}

No contexto da hospitalização pediátrica, conclui-se que o espaço físico-arquitetônico não deve ser um fator a mais de estresse para a criança, o adolescente e seus familiares, visto todos os outros obstáculos que já terão pela frente durante a hospitalização. Mais do que isso, a arquitetura deverá contribuir para o bem-estar de ambos, propondo um local em que haja respeito, dignidade e conforto durante o processo de enfrentamento da doença.

O desafio é pensar ambientes pediátricos como lugares que espelhem significados que darão continuidade ao vivido no cotidiano. Através da aplicação do Poema dos Desejos, foi corroborada a necessidade de que o ambiente deve ser apropriado para as especificidades da infância, em suas diferentes faixas etárias, atento à noção de escala, visando o uso do espaço como uma ferramenta terapêutica e reduzindo a distância entre o paciente e o hospital, já que a criança e o adolescente tendem a associá-lo com o próprio lar. Quando falamos em hospitalização na infância, os resultados demonstram que as necessidades dos pacientes extrapolam o cuidado médico e devem ser consideradas integralmente, envolvendo todos os aspectos da pessoa. Entende-se, assim, a relevância de se pensar o espaço agregando noções de identidade e território, a fim de que tais pacientes identifiquem-se com 0 ambiente, demarquem seus territórios de vivência e mesmo fora da sua rotina natural e cotidiana a criança possa ver quem ela realmente é refletida no ambiente em que está inserida, independente se está em um espaço hospitalar ou não.

\section{REFERÊNCIAS BIBLIOGRÁFICAS}

ALMEIDA, Inez Silva de; RODRIGUES, Benedita Maria do R. D.; SIMOES, Sônia Mara Faria.

Desvelando o cotidiano do adolescente hospitalizado. Revista brasileira de Enfermagem [online].

Brasília: 2005. Disponível em:

http://www.scielo.br.ez25.periodicos.capes.gov.br/scielo.php?script=sci_arttext\&pid=S0034-

$71672005000200003 \&$ Ing=en\&nrm=iso. Acessado em 27 de dezembro de 2011.

BRASIL. Ministério da Saúde. Estatuto da criança e do adolescente. Brasília, DF: Ministério da Saúde, 1990.

FISCHER, Gustave-N. Psicologia Social do Ambiente. Lisboa: Instituto Piaget, 1984.

FUNALFA - Fundação Cultural Alfredo Ferreira Lage (org.). Memória da urbe: bens tombados. Juiz de Fora (MG): FUNALFA Edições, 2004.

HALL, Edward . A Dimensão Oculta. Ed. Martina Fontes. São Paulo, 1977.

MALKIN, Jain. Usando o design baseado em evidências para melhorar a segurança, a qualidade e a experiência do paciente. V CBDEH: São Paulo, 2012.

MITRE, Rosa Maria de Araújo; GOMES, Romeu. A promoção do brincar no contexto da hospitalização infantil como ação de saúde. Ciência e Saúde Coletiva. Rio de Janeiro, 2004. Disponível em: < http://www.scielosp.org/scielo.php?pid=S1413-

81232004000100015\&script=sci_arttext\&tlng=pt>. Acessado em: 13 de novembro de 2010. 


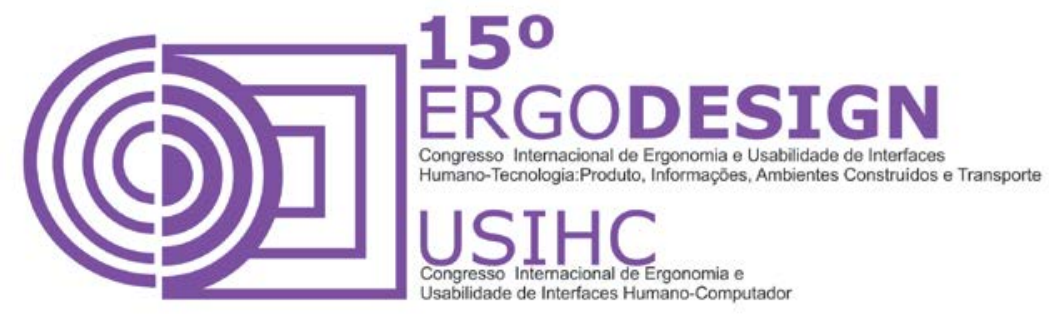

OLIVEIRA, Helena de. A enfermidade sob o olhar da criança hospitalizada. Cadernos de Saúde Pública. Rio de Janeiro, 1993. Disponível em: <http://www.scielosp.org/scielo.php?pid=S0102311X1993000300020\&script=sci_arttext\&tlng=pt >. Acessado em: 14 de novembro de 2010.

OLIVEIRA, Juliana Simili de. Humanização em Saúde: arquitetura em enfermarias pediátricas. Dissertação de Mestrado. Juiz de Fora: Universidade Federal de Juiz de fora, 2012.

RHEINGANTZ, Paulo A.; AZEVEDO. Gisele; BRASILEIRO, Alice; ALCANTARA, Denise de; QUEIROZ, Mônica. Observando a Qualidade do Lugar: procedimentos para o trabalho de campo. [livro eletrônico] Rio de Janeiro: PROARQ/UFRJ-FAU, 2009.

SOMMER, Robert. Espaço Pessoal: as bases comportamentais de projetos e planejamentos. São Paulo: Editora da USP, 1973.

VAN DER VOORDT, Theo J. M.; VAN WEGEN, Herman B. R. Arquitetura sob o olhar do usuário: Programa de Necessidades, Projeto e Avaliação de Edificações. São Paulo: Oficina de Textos, 2013.

WOODWARD, Kathryn. Identidade e diferença: uma introdução teórica e conceitual. In: SILVA, Tomaz Tadeu da (org.). Identidade e diferença: a perspectiva dos estudos culturais. Petrópolis, RJ: Vozes, 2000.

ZEVI, Bruno. Saber ver a arquitetura. São Paulo: Editora Martins Fontes, 2009. 